\title{
A genetic mechanism for the evolution of senescence in Callosobruchus chinensis (the azuki bean weevil)
}

\author{
YOSHINARI TANAKA* \\ Laboratory of Applied Entomology and Nematology, School of Agriculture, Nagoya University, Nagoya 464-01, Japan
}

\begin{abstract}
Heritabilities and genetic correlations of life-history characters (age-specific fecundities and longevity) in azuki bean weevils were estimated. Heritability estimates were moderate or high for longevity and several age-specific fecundities including early fecundity. A genetic correlation was highly negative between longevity and early fecundity. The negative genetic correlation supports the antagonistic pleiotropy theory for the evolution of senescence.

Inbreeding depression for age-specific fecundities was assayed by comparing full-sib mated inbred lines and crosses. There was no tendency for inbreeding depression of fecundities to increase with age. The stability of inbreeding depression at different ages argues against the hypothesis that deleterious mutations accumulated in later ages are one of the causal factors for the evolution of senescence in this insect.
\end{abstract}

Keywords: antagonistic pleiotropy, Callosobruchus chinensis, genetic correlation, heritability, life history.

\section{Introduction}

The evolution of senescence is a controversial topic because it has no direct benefit on fitness, and has important implications for ecological and evolutionary theories. The effect of natural selection declines as age proceeds after the onset of reproduction (Fisher, 1930; Medawar, 1946; Hamilton, 1966; Charlesworth, 1980). This means that any decrease in a fitness character (e.g. fecundity or longevity) has a greater influence on lifetime fitness when it occurs earlier in a life cycle.

Based on such arguments, Medawar (1946) suggested the potential importance, in the evolution of senescence, of deleterious mutations accumulated in later ages. He supposed the deleterious effects of mutations was postponed to later ages by age-of-onset modifiers.

Another explanation is inspired from antagonistic pleiotropy among several fitness components (Medawar, 1946; Williams, 1957; Lande, 1982; Rose, 1982). As an early component contributes more to lifetime fitness than a late one, alleles enhancing early fitness should spread in a population, and senescence could evolve by correlated responses to selection act-

*Present Address: National Institute of Genetics, Mishima 411, Japan. ing on the early component. This scheme is called the antagonistic pleiotropy theory, and is not exclusive to the above-mentioned mutation accumulation theory. This study aims to assess the relative importance of the above two theories in a laboratory population of the azuki bean weevil Callosobruchus chinensis.

The antagonistic pleiotropy hypothesis predicts a negative genetic correlation in fitness between ages, which will be tested in the first experiment. According to the mutation accumulation theory, inbreeding depression on fitness must increase as age advances, provided that the average degree of dominance in deleterious genes does not change with age. I will explore age-specific effects of inbreeding depression on fecundity in the second experiment.

\section{Materials and methods}

\section{Base population}

The base population used here has been maintained under a $25^{\circ} \mathrm{C}, 70 \mathrm{RH} \%$ and $\mathrm{L} 16 / \mathrm{D} 8$ regime with a population size larger than 100 . This laboratory population was founded by blending several dozen weevils collected in the field with a long-standing (more than 550 generations) laboratory population established by Utida (jC-strain; c.f. Utida[1943]). The ratio of the 
numbers of individuals taken from the two sources was about $1 / 1$. After blending, more than 15 generations of random mating elapsed before the onset of experiments.

\section{Experiment I - sib analysis in an outbred population}

About 50 virgin females and 25 virgin males were arbitrarily chosen as parents (dams and sires) from the base population. Each male was allowed to mate with two females, and each female was then transferred into a plastic vial that contained 20 azuki beans (Vigna angularis) as oviposition sites. Offspring larvae were reared in these vials under $25^{\circ} \mathrm{C}, 70 \mathrm{RH} \%$ and $16 \mathrm{~L} / 8 \mathrm{D}$ until adults emerged.

Four adult females were chosen from each newly emerged full-sib cohort and kept individually in plastic vials that contained 20 azuki beans. Each female was supplied with one adult male taken from her full-sib family. Eggs laid on the beans were counted every 3 days and fresh beans were replenished. Five per cent sugar solution was provided every 2 or 3 days as food for the adults. Eggs were counted on five occasions although some individuals did not survive for the full period. Age-specific fecundities are referred to as $F_{1}, F_{2}, \ldots, F_{5}$. All data, including longevity, were transformed to a logarithmic scale.

Because of space limitations the above-described experiment was replicated four times. Data were analysed by a nested ANOVA (Falconer, 1989). Henderson's Method III (Henderson, 1953; c.f. Snedecor \& Cochran, 1967; Sokal \& Rohlf, 1981) was employed to calculate unbiased estimates for the variance components of all traits. The additive genetic variances were determined from between-sire variance components. To calculate standard errors of heritabilities, a resampling method (the Tukey's Jackknife [Arvesen \& Schmit, 1970; Efron, 1982]) was employed. The resampling unit was set as the paternal families. Standard errors for genetic correlations were determined according to Falconer (1989, chapter 19).

\section{Experiment / - inbreeding depression on age- specific fecundities}

Sib-mated lines were founded from 25 adult pairs taken from the base population, and were kept by fullsib mating for 12 generations under $25^{\circ} \mathrm{C}, 70 \mathrm{RH} \%$. Three lines became extinct due to failure in reproduction or offspring hatching.

Five of the 22 inbred lines were chosen arbitrarily and from each of these five virgin females and five males were taken for crossing. These were used to construct diallel crosses consisting of five within-line matings and 20 reciprocal crosses between the five lines. The offspring were reared under $25^{\circ} \mathrm{C}$ and $70 \mathrm{RH} \%$ until the adults emerged. Larval density was controlled at two larvae per bean in order to prevent density effects.

Eggs laid by the adult offspring were counted every other day (on 10 occasions in total) in the same way as in the sib analysis except for frequency of countings.

\section{Results}

\section{Heritabilities and genetic correlations}

Heritabilities were moderate or high in all traits except for $F_{3}$ (Table 1). The estimates are remarkably high in the fecundities $\mathrm{F}_{1}$ and $\mathrm{F}_{4}$.

High heritabilities in early fecundity of this insect have also been observed by Nomura \& Yonezawa (1990) and Tanaka (1991).

The genetic correlation between $\mathrm{LN}$ and $\mathrm{F}_{1}$ is highly negative (Table 2 ), while slightly positive between $\mathrm{LN}$ and the rest of the fecundities. All correlations except for the pair of $F_{1}$ and $F_{2}$ are positive among age-specific fecundities. The combinations of $F_{1}-F_{4}, F_{1}-F_{5}$ and $\mathrm{F}_{4}-\mathrm{F}_{5}$ have estimated genetic correlations exceeding 1.0 probably due to large sampling errors of heritabilities in $F_{4}$ and $F_{5}\left(F_{3}\right.$ was excluded from the calculations because of its low heritability).

\section{Principal components}

The correlation structure was analysed further using a multivariate analysis (principal component analysis; PCA). Two principal components could be extracted, which together explained 100 per cent of the total variance (Table 3 ). In the first principal axis, the vector has highly positive coefficients and factor loadings with all fecundity traits. Longevity has no significant contribution to this component, which suggests that survival has a different genetic basis to that of

Table 1 Heritability estimates

\begin{tabular}{ll}
\hline Character & Heritability \\
\hline $\mathrm{F}_{1}$ & $1.06(1.17 \pm 0.189)$ \\
$\mathrm{F}_{2}$ & $0.56(0.60 \pm 0.199)$ \\
$\mathrm{F}_{3}$ & $0.06(0.06 \pm 0.252)$ \\
$\mathrm{F}_{4}$ & $1.04(1.02 \pm 0.527)$ \\
$\mathrm{F}_{5}$ & $0.70(0.72 \pm 0.376)$ \\
$\mathrm{LN}$ & $0.73(0.74 \pm 0.226)$ \\
\hline
\end{tabular}

The parenthetic values are jackknife estimates \pm standard errors. See text for abbreviations. 
Table 2 Genetic correlations in life history characters

\begin{tabular}{llllr}
\hline Character & $F_{2}$ & $F_{4}$ & $F_{5}$ & \multicolumn{1}{l}{$L$} \\
\hline$F_{1}$ & $-0.11 \pm 0.12$ & 1.00 & 1.00 & $-0.91 \pm 0.01$ \\
$F_{2}$ & & $0.14 \pm 0.18$ & $0.87 \pm 0.02$ & $0.28 \pm 0.11$ \\
$F_{4}$ & & & 1.00 & $0.21 \pm 0.15$ \\
$F_{5}$ & & & & $0.34 \pm 0.12$ \\
\hline
\end{tabular}

Table 3 Eigen vectors and factor loadings extracted from genetic correlations

\begin{tabular}{lll}
\hline Character & 1st PC & 2nd PC \\
\hline $\mathrm{F}_{1}$ & $0.541(0.959)$ & $0.449(0.624)$ \\
$\mathrm{F}_{2}$ & $0.241(0.427)$ & $-0.503(-0.698)$ \\
$\mathrm{F}_{4}$ & $0.541(0.959)$ & $-0.018(-0.025)$ \\
$\mathrm{F}_{5}$ & $0.595(1.054)$ & $-0.254(-0.353)$ \\
$\mathrm{LN}$ & $-0.053(-0.093)$ & $-0.693(-0.961)$ \\
$\mathrm{cc}(\%)$ & 62.8 & 101.4 \\
\hline
\end{tabular}

$\mathrm{cc}=$ cumulative contribution.

The values in parentheses are factor loadings.

reproduction. In the second axis, the factor loadings show a large positive value for $F_{1}$ and negative values for $\mathrm{F}_{2}$ and $\mathrm{LN}$. The signs of the contribution are opposite between $F_{1}$ and later fecundities or longevity. Thus, this component appears to identify alleles which enhance early reproduction and tend to reduce life span.

\section{Comparison between the inbred lines and the crosses}

Mean age-specific fecundities of the crosses and the inbred lines were compared and the inbred lines were less fecund than the crosses in all age-classes except for $F_{10}$ (data not shown). The average life-time fecundity of the inbred lines was $90.7 \pm 22.5$ (sample size was $n=48$ ) while that for the crosses was $103.4 \pm 27.4(n=79)$. The difference of 12.3 per cent in the mean fecundities is highly significant $(P<0.01[t$-test $])$.

Standard deviations in the age-specific fecundities varied with the means for both the inbred lines and the crosses. Furthermore they exceeded 10 per cent of the means. For this reason, logarithmically transformed data were used to examine whether or not inbreeding depression changes with age.

Regression of the differences in fecundities between the inbred lines and the crosses (i.e. cross - inbred) on age classes was not significant (the slope was -0.038 , $P>0.05)$, which indicates that inbreeding depression on fecundity does not increase with age.

\section{Discussion}

The negative genetic correlation between early fecundity and longevity indicates that, in accord with the antagonistic pleiotropy hypothesis, senescence (reduction in longevity) could evolve by correlated genetic responses to selection acting on early reproduction. Furthermore, inbreeding depression in fecundity, which was stable with age, provided no support for the alternative mutation-accumulation hypothesis. Similar conclusions arose from a separate, independent experiment, which used the same base population but different inbred lines (Tanaka, 1990).

Previous laboratory experiments with Drosophila melanogaster have demonstrated negative genetic correlations in early and late ages (Rose \& Charlesworth, 1981a; Luckinbill et al., 1984; Service \& Rose, 1985; Clark, 1987). Several selection experiments have indicated genetic responses in longevity, some of which were accompanied by changes in lifetime fecundity (Luckinbill et al. 1984; Luckinbill \& Clare, 1985; but Rose \& Charlesworth, 1981b). A delay in senescence tends to be related to a reduction in early fecundity (Luckinbill et al., 1984). This supports the antagonistic pleiotropy theory.

Several other studies have focused on the mutation accumulation theory (Rose \& Charlesworth, 1981a; Service et al., 1988). Kosuda (1985) found that male mating ability in Drosophila had larger variances in later ages, and the relative mating ability of the second chromosomal homozygotes as compared to the heterozygotes decreased considerably in later ages. Service $e t$ al. (1988) performed reverse selection on early fecundity after long-term selection on late fecundity. Based on the absence of responses to the reverse selection, they suggested the possibility of mutation accumulation.

Age-specific effects of inbreeding on fitness components may reveal the distribution of deleterious mutations during a life cycle. In most cases the causal effect of inbreeding depression is increased homozygosity of (incompletely) recessive deleterious genes (Simmons \& Crow, 1977; Charlesworth \& Charlesworth, 1987; Falconer, 1989). Then, if the association between deleterious effects and the degree 
of dominance does not change with age, inbreeding depression is predicted to be larger in later ages. However, this test is based on an assumption of constancy in dominance during the life cycle. If this is violated, agespecific effects of inbreeding may not represent the true distribution pattern of deleterious mutations. When the degree of dominance is smaller (i.e. deleterious alleles are more recessive) in earlier periods, the total amount of genotypic effects could be stable with age, irrespective of heterozygosity. It is known that the degree of dominance in deleterious genes tends to be inversely proportional to their effects on fitness (Simmons \& Crow, 1977; Charlesworth \& Charlesworth, 1987), but further studies will be required to assess the age-specificity of dominance.

\section{Acknowledgements}

For comments on an earlier version of the manuscript I would like to thank T. Hansen, D. Houle, H. Morishima and T. Nomura. Y. Ito encouraged the work. This study was supported by a JSPS postdoctoral fellowship. I would like to thank an anonymous referee for the time and effort spent on my manuscript.

\section{References}

ARVESEN, J. N. AND SCHMIT, T. H. 1970. Robust procedures for variance component problems using the jackknife. Biometrics, 26, 677-686.

CHARLESWORTH, B. 1980. Evolution in Age-Structured Populations. Cambridge University Press, Oxford.

CHARLESWORTH, D. AND CHARLESWORTH, B. 1987. Inbreeding depression and its evolutionary consequences. Ann. Rev. Ecol. Syst., 18, 237-268.

CLARK, A. G. 1987. Senescence and the genetic correlation hang-up. Am. Nat., 129, 932-940.

EFRON, B. 1982. The Jackknife, the Bootstrap and Other Resampling Plans. SIAM. Philadelphia.

FALCONER, D. S. 1989. Introduction to Quantitative Genetics, 3rd edn. Longman, New York.

FISHER, R. A. 1930. The Genetical Theory of Natural Selection. Clarendon Press, Oxford.

HAMILTON, W. D. 1966. The moulding of senescence by natural selection. J. Theor. Biol., 12, 12-45.

HENDERSON, C. R. 1953. Estimation of variance and covariance components. Biometrics, 9, 226-252.
KosUDA, K. 1985. The aging effect of male mating activity in Drosophila melanogaster. Behav. Genet., 15, 297-303.

LANDE, R. 1982. A quantitative genetic theory of life history evolution. Ecology, 63, 607-615.

LUCKINBILL, L. S., ARKING, R., CLARE, M. J., CIROCCO, W. C. AND BUCK, S. A. 1984. Selection for delayed senescence in Drosophila melanogaster. Evolution, 38, 996-1003.

LUCKINBILL, L. S. AND CLARE, M. 1985. Selection for life span in Drosophila melanogaster. Heredity, 55, 6-18.

MEDAWAR, P. B. 1946 . Old age and natural death. Modern Quart., 2, 30-49.

NOMURA, T. AND YONEZAWA, K. 1990. Genetic correlations among life history characters of adult females in the azuki bean weevil, Callosobruchus chinensis (L) (Coleoptera: Bruchidae). Appl. Ent. Zool., 25, 423-430.

ROSE, M. R. 1982. Antagonistic pleiotropy, dominance and genetic variation. Heredity, 48, 63-78.

ROSE, M. R. AND CHARLESWORTH, B. 1981a. Genetics of life history in Drosophila melanogaster. I. Sib analysis of adult females. Genetics, 97, 173-186.

ROSE, M. R. AND CHARLESWORTH, B. 1981b. Genetics of life history in Drosophila melanogaster. II. Exploratory selection experiments. Genetics, 97, 187-196.

SERVICE, P. M. AND ROSE, M. R. 1985. Genetic variation among life history components: the effects of novel environments. Evolution, 39, 943-945.

SERVICE, P. M., HUTCHINSON, E. W. AND ROSE, M. R. 1988. Multiple genetic mechanisms for the evolution of senescence in Drosophila melanogaster. Evolution, 42, 708-716.

SIMMONS, M. J. AND CROW, J. F. 1977. Mutations affecting fitness in Drosophila populations. Ann. Rev. Genet., 11, 49-78.

SNEDECOR, G. W. AND COCHRAN, W. G. 1967. Statistical Methods, 6th edn. Iowa State University Press, Ames, lowa.

SOKAL, R. R. AND ROHLF, F. J. 1981. Biometry, 2nd edn. W. H. Freeman, San Francisco.

TANAKA, Y. 1990. Age specificity of inbreeding depression during a life cycle of Callosobruchus chinensis (Coleoptera: Bruchidae). Res. Popul. Ecol., 32, 329-335.

TANAKA, Y. 1991. Genetic variation in age-specific fecundity of the adzuki bean weevil Callosobruchus chinensis (Coleoptera: Bruchidae). Appl. Ent. Zool., 26, 263-265.

UTIDA, s. 1943. Studies on the experimental population of the azuki bean weevil, Callosobruchus chinensis (L). VIII. Statistical analysis of the frequency distribution of the emerging weevils on beans. Mem. Coll. Agr. Kyoto. Imp. Univ. 54, 1-22.

williams, G. C. 1957. Pleiotropy, natural selection and the evolution of senescence. Evolution, 11, 398-411. 